\title{
Central Yamal vegetation monitoring based on Sentinel-2 and Sentinel-1 imagery
}

\author{
Tatiana G. Plutalova ${ }^{1}$, Kanayim Teshebaeva ${ }^{2}$, Dmitry N. Balykin ${ }^{1}$, \\ Alexander V. Puzanov ${ }^{1}$, Jacobus van Huissteden ${ }^{2}$, Mikhail I. Koveshnikov ${ }^{1}$, \\ Olga V. Lovtskaya ${ }^{1}$ and Nelly M. Kovalevskaya ${ }^{1}$ \\ ${ }^{1}$ Institute for Water and Environmental Problems SB RAS, Barnaul, Russia \\ ${ }^{2}$ VU University, Amsterdam, the Netherlands
}

\begin{abstract}
In this study fusion of optical (Sentinel-2) and radar (Sentinel-1) imagery is presented for vegetation cover classification in polar Arctic environment of the Western Siberia. Sentinel-1 and Sentinel-2 images were analyzed using parametric rule classification. Results showed significantly improved land cover classification results based on contextual analysis. Synergy of Sentinel-2 bands 4 and 3 and Sentinel-1 dual polarization VV and VH images increased the classification accuracy significantly. Specifically, classification accuracy increased for two classes - Erect dwarf-shrub tundra with $6 \%$ and Fresh Water with $10 \%$. The classification accuracy as well test sites were analyzed using in situ data collected during three fieldwork campaigns in August-September (2016-2018) in the surrounding of Bovanenkovo settlement.
\end{abstract}

\section{Keywords}

Central Yamal, vegetation, Sentinel-2, Sentinel-1, classification, Maximum Likelihood, contextual analysis.

\section{Introduction}

Arctic vegetation cover is significantly affected by recently changing climate and environmental conditions $[1,2]$. Meanwhile, tundra vegetation is crucial for permafrost dynamics and feedbacks between the Earth surface and the atmosphere [3]. Since a vegetation effect on heat and moisture exchange between the soil and atmosphere is significant (in fact, "soil temperature and humidity depend on vegetation cover" [4]), vegetation monitoring in the Arctic is essential.

Vegetation cover development (primarily, its height and density) is of particular importance. Vegetation height is a key biophysical control on and proxy for environmental conditions. For example, shrub height influences snow trapping and snowmelt, which impact ground thermal conditions [5]. The mapping of areas with different height vegetation for the circumpolar Arctic tundra biome is of interest for a wide range of applications, including biomass and habitat studies as well as permafrost modeling in the context of climate change.

Poorly studied climate-related dynamics of vegetation is the main reason for great uncertainty of forecasts. The most effective calculations relating to vegetation dynamics can be implemented on the basis of remote sensing (RS) data providing the detailed information on vegetation cover (class, thickness, height, etc.) in different spectral, spatial and temporal/seasonal aspects.

SDM-2021: All-Russian conference, August 24-27, 2021, Novosibirsk, Russia

$\bigoplus$ plutalova.tg@gmail.com (T.G. Plutalova); j.van.huissteden@vu.nl (J.v. Huissteden)

(c) (1) 8021 Copyright for this paper by its authors. Use permitted under Creative Commons License Attribution 4.0 International (CC BY 4.0).

CEUR Workshop Proceedings (CEUR-WS.org) 
Existing approaches to the vegetation cover analysis based on RS methods are primarily focused on exploiting optical RS data.

Most studies of Arctic vegetation are based on low-resolution satellite data, such as AVHRR (Advanced Very High Resolution Radiometer, $1.09 \mathrm{~km}$ nadir resolution) or MODIS (mediumresolution spectrometer, resolution $\geq 250 \mathrm{~m}$ ) ones $[6,7,8]$. However, gradual changes in vegetation are hard to detect from coarse-resolution data due to landscape heterogeneity and lack of pure pixels. Thus, AVHRR observations show a positive trend in tundra greening from 1982 to 2010, the overall mean greenness of northern hemisphere tundra has increased by about $8 \%$ [7]. There is, however, a considerable unexplained regional variation in the observed NDVI trends, and the climate drivers are not well understood.

High-resolution satellites (SPOT, Landsat, RapidEye, Sentinel-2) detect vegetation variability much better $[9,10,11]$. In particular, the European land cover mapping is based on Sentinel-2 images [12].

Sentinel-2 studies are often limited to analyzing the efficiency of individual bands and vegetation indices [3]. Also, because of the Arctic vegetation system complexity, the mapping of technogeneous disturbance of tundra vegetation in Yamal-Nenets Autonomous Okrug was based on visual interpretation of Landsat- 8 and Sentinel-2 imagery [13]. Many aspects of parametric classification of Sentinel-2 imagery as well as subsequent analysis of dynamics of tundra vegetation classes remain poorly studied. Among major tasks is the mapping of Central Yamal vegetation based on the parametric rule classification of multispectral Sentinel-2 imagery and field data.

As a complement to optical RS techniques, vegetation cover maps derived from synthetic aperture radar (SAR) systems are an important tool for monitoring and dynamics analyzing of vegetation. SAR data independence solar irradiance and cloud cover is a significant reason for using this technique for vegetation cover classification, especially in northern latitude vegetation where the acquisition of optical data is hindered by frequent cloud cover. In addition, the sensitivity of radar signals to moisture content and textural properties of vegetation may separate vegetation classes, particularly when optical sensors are saturated over dense vegetation. Several studies have used SAR images for tundra vegetation classification. A Bayesian Maximum Likelihood (ML) Classifier was applied to SAR imagery covering the boreal forest region (northern Canada) during the peak of the growing season demonstrating the overall accuracy of the classification up to $92 \%$ [14]. The usage of Radarsat-2 SAR data for the modeling of aboveground phytomass for high arctic environment indicates that SAR data are sensitive for specific classes of tundra cover (in particular, polar semi-desert, mesic heath, wet sedge) [15]. Mosaics of summer and winter Japanese Earth Resources Satellite 1 (JERS-1) SAR imagery were employed for the mapping of vegetated wetland of Alaska, including moss, lichen and shrubs [16]. The per-class average error rate for aggregate wetlands classes ranged between $5.0 \%$ and $30.5 \%$, and the total aggregate accuracy calculated based on all classified pixels was $89.5 \%$.

Recent advancements in imaging science have provided finer spatial, spectral, and temporal resolution. In addition, non-optical data sources such as SAR data have been shown to add value when combined with optical remote sensing data. In particular, for Danube delta wetlands the results for Sentinel-2 classification performance is $87.5 \%$ of mean accuracy, synergy of Sentinel-2 and Sentinel-1 improves the classification performance up to $97.1 \%$ [17]. 
A combination of Sentinel-2 and Sentinel-1 to derive tundra vegetation height based on vegetation indices for the territory of the Yamal and Gydan Peninsulas has demonstrated that this method is effective only for mapping vegetation of limited height [5]. It is known also that vegetation indices developed in optical remote sensing can provide the information only on the surface of vegetation canopy [17].

Supervised and unsupervised classifications for combining optical data (Landsat-8) with two types of SAR data (TerraSAR-X and Radarsat) were employed for the mapping of tundra vegetation in Richards Island, Canada [18]. The classification accuracies were analyzed using test data collected during three fieldwork campaigns. The optical data offered an acceptable initial accuracy for the land cover classification for five tundra cover types. The overall accuracy was increased by the combination of SAR and optical data:

- up to $71 \%$ for unsupervised classification (Landsat 8 and TerraSAR-X);

- up to $87 \%$ for supervised classification (Landsat 8 and Radarsat-2).

It is worth noting that a new European CLC (Copernicus Land Cover) standard for land monitoring in the next decade is being currently developed on the basis of classification of time series of Sentinel-1 and Sentinel-2 [19].

Thus, the second task arising in the context of Central Yamal vegetation monitoring is to determine the influence of SAR dimension (VV and VH polarizations of Sentinel-1) on vegetation classification based on optical (Sentinel-2) data.

\section{Materials and methods}

\subsection{Study area}

The study area characterized by subarctic climate is located in the permafrost tundra zone of the central part of Yamal Peninsula (Figures 1 and 2). The terrain is flat (its heights do not exceed $100 \mathrm{~m}$ a.s.l.) with extensive river network and numerous thermokarst lakes.

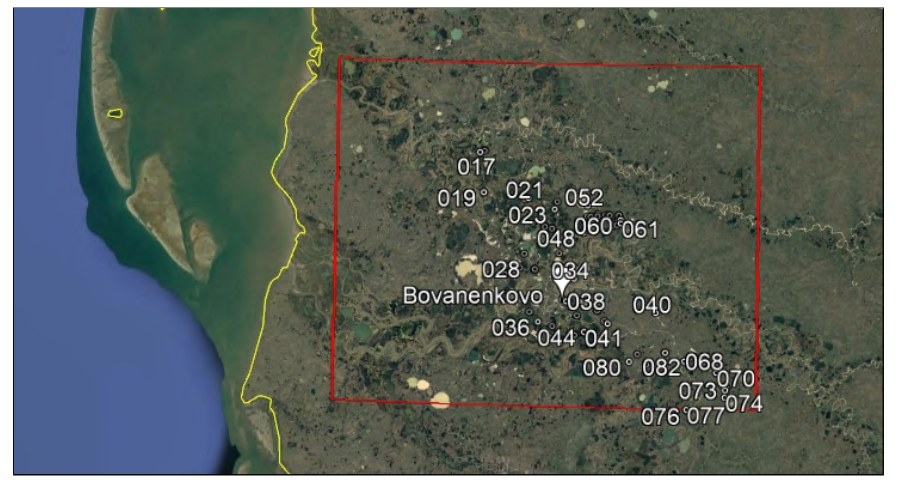

Figure 1: Study area. 
a

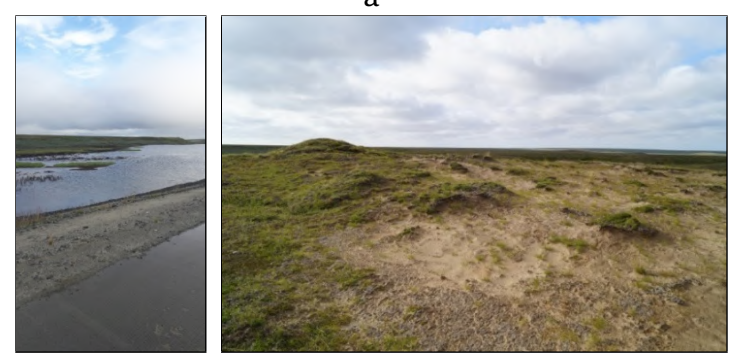

b

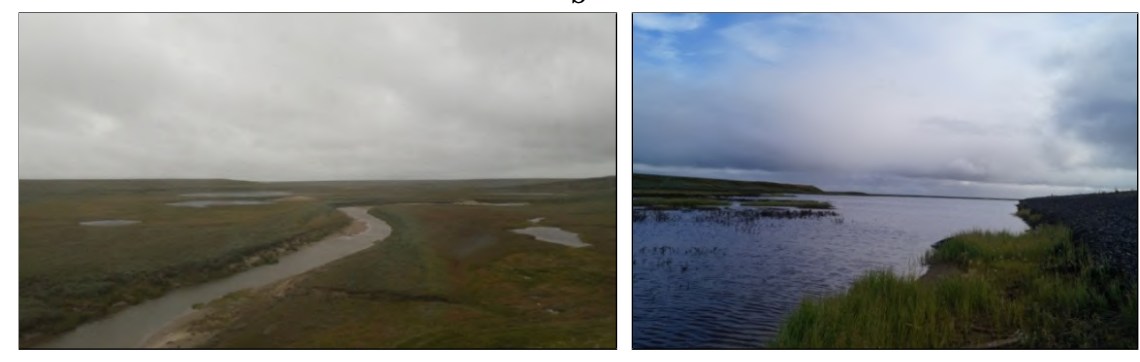

C

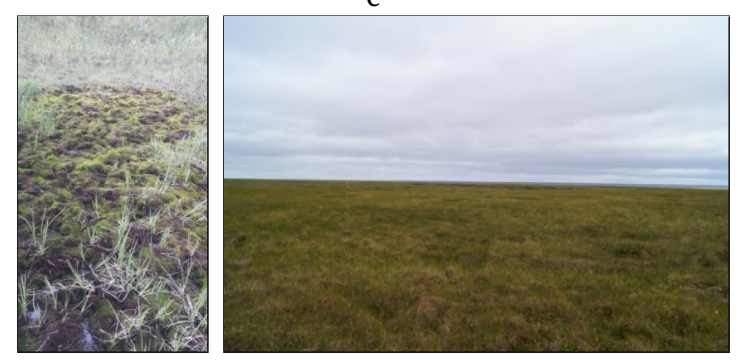

$\mathrm{d}$

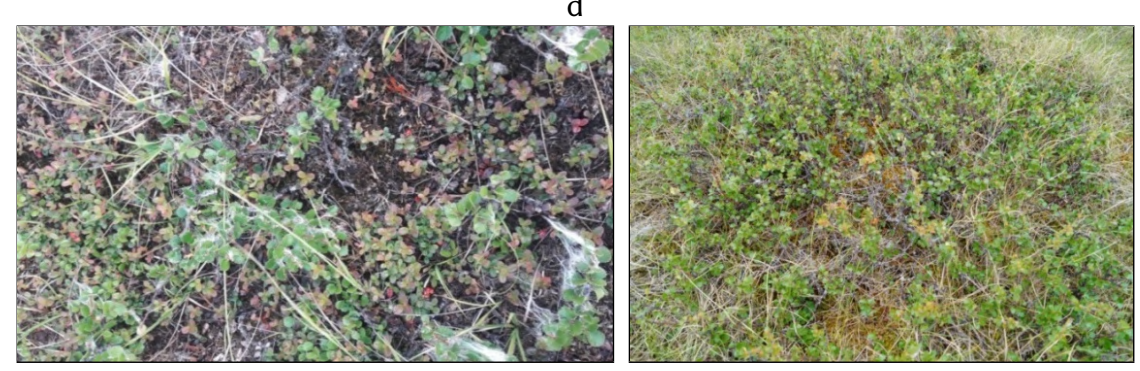

e
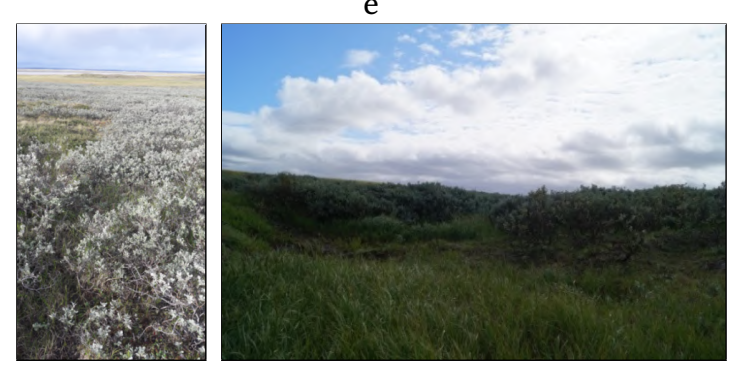

Figure 2: Field photographs of Central Yamal showing: Barrens (a); Fresh Water (b); Sedge, moss, lowshrub wetland (c); Erect dwarf-shrub tundra (d); Low-shrub tundra (e) (photo: Balykin D., Sysoeva T.). 


\subsection{Datasets}

In this study, multispectral data of Sentinel-2, SAR data of Sentinel-1 and field data of AugustSeptember (2016-2018) are used (Tables 1 and 2).

The Copernicus Sentinel Program by the European Space Agency (ESA) is a satellite program with the open source of completely transparent real-time data (retrieved from Alaska Satellite Facility processed by ESA-2019). Both Sentinel-1 and Sentinel-2 data are used to compute the displacement and evaluate relationships between the displacement and environmental variables. The Sentinel data products are made available systematically and free of charge to all data users including the general public, scientific and commercial users.

The Sentinel-1 constellation consists of 2 satellites, Sentinel-1A and Sentinel-1B, which have been operating since October 2014 and April 2016. The images are available in the Level 1 Ground Range Detected (GRD). Level-1 GRD data with High Resolution HR), 250 km Interferometric Wide (IW) swath images in C-band through all-weather conditions with $20 \mathrm{~m}$ ground resolution. Images are available in dual VV and VH polarizations. Sentinel-1 also has frequent imagery over this area of Yamal; since 2017, it is a focus area for crater outburst monitoring.

The Sentinel-2 constellation consists of 2 satellites, Sentinel-2A and Sentine-2B, which have been operating since June 2015 and March 2017. Their spatial resolution is 10, 20, or $60 \mathrm{~m}$ depending on the bands, providing a 5 -day temporal resolution by combining the two satellites, and a $290 \mathrm{~km}$ swath. Images were downloaded with processing level $1 \mathrm{C}$ on the https://earthexplorer.usgs.gov/platform.

\section{Table 1}

Satellite data.

\begin{tabular}{lccccc}
\hline No. & Data & Type & $\begin{array}{c}\text { Spatial Resolution } \\
\text { (bands) }\end{array}$ & Date of Acquisition & $\begin{array}{c}\text { Polarization } \\
\text { Channels/Spectral Bands }\end{array}$ \\
\hline & & & $10 \mathrm{~m}(2,3,4,8)$, & 12.08 .2016 & \\
1. & Sentinel-2 & Optical & $20 \mathrm{~m}(5,6,7,8 \mathrm{a})$, & 24.08 .2017 & 13 multispectral bands \\
& & & $60 \mathrm{~m}(1,9,10)$ & 21.07 .2018 & \\
2. & Sentinel-1 & SAR & $20 \mathrm{~m}$ & 20.08 .2018 & VV and VH polarization \\
\hline
\end{tabular}

\section{Table 2}

Field data.

\begin{tabular}{|c|c|c|c|c|}
\hline \multirow{2}{*}{ Symbol } & \multirow{2}{*}{ Class } & \multicolumn{3}{|c|}{ Field data of August-September } \\
\hline & & 2016 & 2017 & 2018 \\
\hline $\mathrm{B}$ & Barrens & 411 & 411 & 437 \\
\hline FW & Fresh water & 687 & 687 & 728 \\
\hline W3 & Sedge, moss, low-shrub wetland & 619 & 619 & 656 \\
\hline S1 & Erect dwarf-shrub tundra & 21 & 21 & 22 \\
\hline \multirow[t]{2}{*}{ S2 } & Low-shrub tundra & 249 & 249 & 264 \\
\hline & TOTAL: & 1987 & 1987 & 2107 \\
\hline
\end{tabular}




\subsection{Methodology}

\subsubsection{Land cover classes of Central Yamal}

Central Yamal land cover is characterized by five dominant classes [1, 2, 7, 8]: Barrens (B); Fresh water (FW); Sedge, moss, low-shrub wetland (W3); Erect dwarf-shrub tundra (S1); Low-shrub tundra (S2) (see Table 2).

\subsubsection{Image processing and analysis}

Atmospheric correction of Sentinel-2 (A, B) scenes was performed using module Sen2Cor of SNAP software.

To map vegetation cover, we applied the supervised classification approach for both Sentinel-2 imagery and synergy of Sentinel-2 and Sentinel-1 imagery. The supervised classification was done using ML Classifier implemented in ERDAS Imagine. This method has been shown in previous works to be efficient for the classification of general land cover types by optical and SAR imagery $[14,18]$.

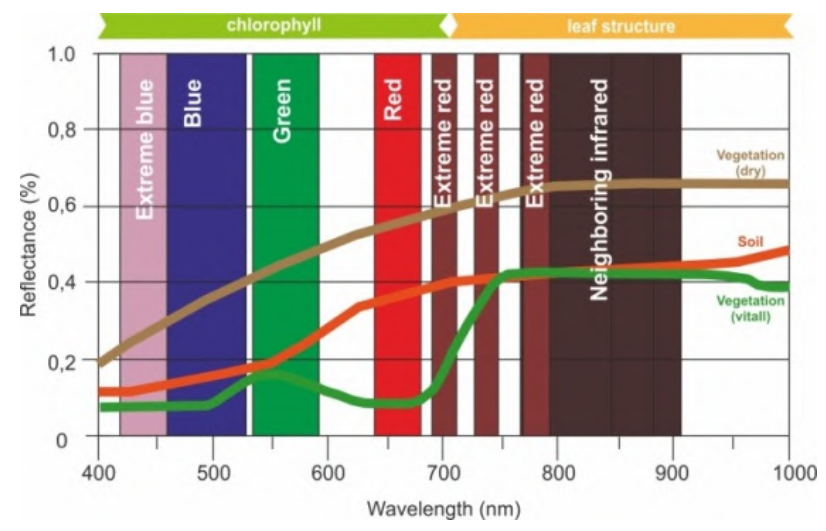

Figure 3: Spectral bands of Sentinel-2.

\section{Table 3}

Combinations of Sentinel-2 bands [20] and Sentinel-1 VV/VH-polarizations.

\begin{tabular}{|c|c|c|c|c|c|c|}
\hline Combination & $\mathrm{R}^{1}$ & $\mathrm{G}^{1}$ & $\mathrm{~B}^{1}$ & $\mathrm{R}^{2}$ & $\mathrm{G}^{2}$ & $\mathrm{~B}^{2}$ \\
\hline Natural Colors S-2: RGB $=(4,3,2)$ & 4 & 3 & VV & 4 & 3 & $\mathrm{VH}$ \\
\hline False color Infrared S-2: $\mathrm{RGB}=(8,4,3)$ & 8 & 4 & VV & 8 & 4 & $\mathrm{VH}$ \\
\hline $\begin{array}{l}\text { False color Urban } \mathrm{S}-2: \mathrm{RGB}=(12,11,4) \\
\text { Atmospheric penetration } \mathrm{S}-2: \mathrm{RGB}=(12,11,8 a)\end{array}$ & 12 & 11 & VV & 12 & 11 & $\mathrm{VH}$ \\
\hline $\begin{array}{l}\text { Vegetation Analysis S-2: } \mathrm{RGB}=(11,8,4) \\
\text { Agriculture } \mathrm{S}-2: \mathrm{RGB}=(11,8,2)\end{array}$ & 11 & 8 & VV & 11 & 8 & $\mathrm{VH}$ \\
\hline $\begin{array}{c}\text { Healthy vegetation } \mathrm{S}-2: \operatorname{RGB}=(8,11,2) \\
\text { Land/Water } \mathrm{S}-2: \operatorname{RGB}=(8,11,4)\end{array}$ & 8 & 11 & VV & 8 & 11 & $\mathrm{VH}$ \\
\hline $\begin{array}{l}\text { Natural Colors with Atmospheric Removal S-2: } \mathrm{RGB}=(12,8,3) \\
\text { Shortwave Infrared } \mathrm{S}-2: \mathrm{RGB}=(12,8,4)\end{array}$ & 12 & 8 & VV & 12 & 8 & $\mathrm{VH}$ \\
\hline
\end{tabular}


The supervised ML classification was run in the following steps.

(1) Training data: creating spectral signature for each supervised training sample (area of interest) derived from ground truth data.

(2) Maximum-Likelihood Classification: classification based on the minimum Mahalanobis distance.

A preliminary visual pattern analysis was performed for combined optical and SAR data on the basis of

1) assumption that high-resolution SAR data makes it possible to use textural (contextual) characteristics

2) RGB combinations relying on band spectral properties of Sentinel-2 (Figure 3) and VV/VH polarizations of Sentinel-1 (Table 3).

\section{Results}

\subsection{Results of Sentinel-2 data processing}

Figure 4 presents the results of Sentinel-2 classification for the study territory in 2016-2018. During this period, there was the total reduction (from $28 \%$ to 9\%) of open (free from vegetation) areas (Figure 5). At the same time, there was an overall increase in areas related to vegetation:

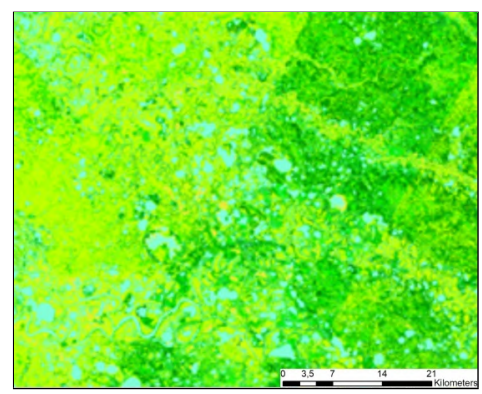

b

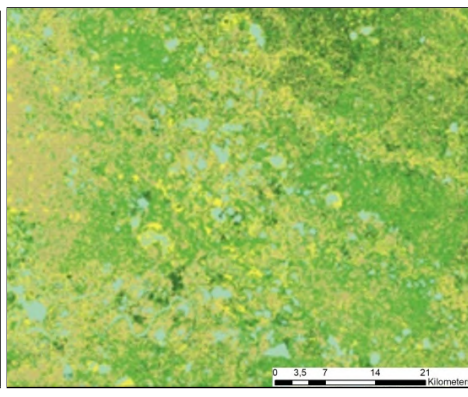

$\square$ B $\square$ FW $\square$ W3 $\square$ S1 $\square$ S2
C

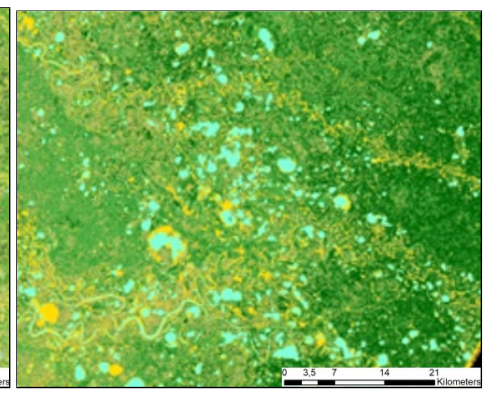

Figure 4: ML classification results for Sentinel - 2 scenes: 12.08.2016 (a), 24.08.2017 (b) and 21.07.2018 (c).

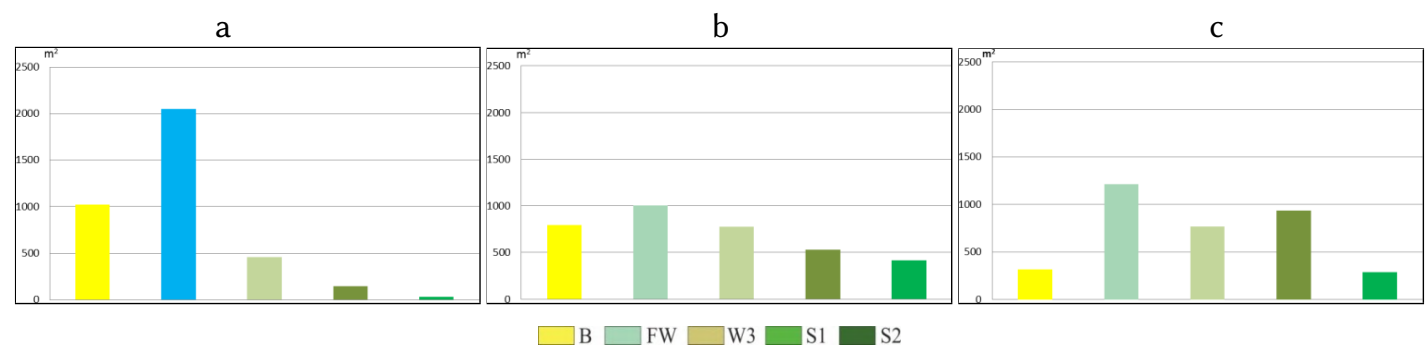

Figure 5: Distribution of class areas based on Sentinel-2 data processing: 12.08.2016 (a), 24.08.2017 (b) and 21.07.2018 (c). 
- the largest increase occurred for Low-shrub tundra (S2), i.e. 10 times (2016-2017);

- the increase from 3\% to 27\% occurred for Erect dwarf-shrub tundra (S1) (2016-2018);

- the twofold increase occurred for Sedge, moss, low-shrub wetland (W3) (2016-2017).

Fresh Water class is predominant on the territory of Central Yamal. The total area of water bodies in 2018 was 34\% (Figure 5, c). The total area of vegetation classes is 57\%, 27\% of which account for Erect dwarf-shrub tundra (S1). Open areas and sands occupy $9 \%$ of the study territory.

\subsection{Results of combined Sentinel-2 and Sentinel-1 data processing}

For co-processing, Sentinel-2 and Sentinel-1 scenes of 2018 were used (see Table 1).

Qualitative differences in visual representations of Sentinel-2 and Sentinel-1 synergy make it possible to choose combinations for the most effective representation of target classes (Table 4). For some combinations, there is decrease $(-)$ and/or increase $(+)$ in the highlighting of anthropogenic classes (Barrens, Fresh Water). For example, for $\mathrm{R}^{1} \mathrm{G}^{1} \mathrm{~B}^{1}=(8,11, V V)$ the highlighting of Barrens decreases and the highlighting of Fresh Water increases.

The results obtained for combinations $\mathrm{R}^{1} \mathrm{G}^{1} \mathrm{~B}^{1}=(4,3, \mathrm{VV})$ and $\mathrm{R}^{2} \mathrm{G}^{2} \mathrm{~B}^{2}=(4,3, \mathrm{VH})$ were thoroughly studied for

- pixel-wise ML classification (Table 5, Figure 6);

- ML classification based on contextual analysis (Table 6, Figure 7).

It is appeared that contextual analysis can significantly improve the results compared to pixel-by-pixel processing. For Sentinel-2 data, a significant improvement occurs for all classes, except for Fresh Water (yet, high accuracy of $90 \%$ remains for this class). For the synergy of Sentinel-2 and Sentinel-1 data, the improvement occurs for almost all classes (up to 100\%).

Table 4

Class highlighting for synergy of Sentinel-2 and Sentinel-1.

\begin{tabular}{|c|c|c|c|c|c|}
\hline \multirow[b]{2}{*}{ Combination } & \multirow[b]{2}{*}{$\begin{array}{l}\mathrm{R}^{1} \mathrm{G}^{1} \mathrm{~B}^{1} \\
\mathrm{R}^{2} \mathrm{G}^{2} \mathrm{~B}^{2}\end{array}$} & \multicolumn{4}{|c|}{ Object highlighting efficiency } \\
\hline & & $\begin{array}{c}\text { Natural } \\
\text { objects }(\mathrm{N}) \\
\text { Anthropogenic } \\
\text { objects }(\mathrm{A})\end{array}$ & Vegetation classes & $\begin{array}{c}\text { Barrens } \\
(+/-)\end{array}$ & $\begin{array}{l}\text { Fresh } \\
\text { Water } \\
(+/-)\end{array}$ \\
\hline Natural Colors & $\begin{array}{l}4,3, \mathrm{VV} \\
4,3, \mathrm{VH}\end{array}$ & $\begin{array}{c}\mathrm{N}, \mathrm{A} \\
\text { (equally } \\
\text { effective) }\end{array}$ & $\begin{array}{l}\text { Difficult to discern, } \\
\text { transitional areas }\end{array}$ & + & + \\
\hline False Color Infrared & $\begin{array}{l}8,4, \mathrm{VV} \\
8,4, \mathrm{VH}\end{array}$ & A & $\begin{array}{l}\text { Difficult to discern, } \\
\text { no clear contours }\end{array}$ & + & - \\
\hline $\begin{array}{c}\text { False Color Urban, } \\
\text { Atmospheric penetration }\end{array}$ & $\begin{array}{l}12,11, \mathrm{VV} \\
12,11, \mathrm{VH}\end{array}$ & $\begin{array}{l}\text { A (water, } \\
\text { buildings) }\end{array}$ & W3, S1 & + & + \\
\hline $\begin{array}{c}\text { Vegetation Analysis, } \\
\text { Agriculture }\end{array}$ & $\begin{array}{l}11,8, \mathrm{VV} \\
11,8, \mathrm{VH}\end{array}$ & $\mathrm{N}$ & W3, S1, S2 & - & + \\
\hline $\begin{array}{l}\text { Healthy Vegetation, } \\
\text { Land/Water }\end{array}$ & $\begin{array}{l}8,11, \mathrm{VV} \\
8,11, \mathrm{VH}\end{array}$ & $\mathrm{N}$ & W3, S1, S2 & - & + \\
\hline
\end{tabular}


Table 5

Results of pixel-wise ML classification.

\begin{tabular}{|c|c|c|c|}
\hline \multirow[b]{2}{*}{ Class } & \multicolumn{3}{|c|}{$\%$ of matches with test set } \\
\hline & $\begin{array}{c}\text { Sentinel-2 } \\
\mathrm{RGB}=(4,3,2)\end{array}$ & $\begin{array}{l}\text { Sentinel-2 \& Sentinel-1 } \\
\mathrm{R}^{1} \mathrm{G}^{1} \mathrm{~B}^{1}=(4,3, \mathrm{VV})\end{array}$ & $\begin{array}{c}\text { Sentinel-2 \& Sentinel- } 1 \\
\mathrm{R}^{2} \mathrm{G}^{2} \mathrm{~B}^{2}=(4,3, \mathrm{HV})\end{array}$ \\
\hline $\begin{array}{c}\text { Sedge, moss, } \\
\text { low-shrub wetland }\end{array}$ & 36.9 & 11.6 & 11.5 \\
\hline Erect dwarf-shrub tundra & 73.7 & 80.7 & 80.5 \\
\hline Low-shrub tundra & 66.8 & 15.4 & 12.6 \\
\hline Barrens & 66.5 & 41.3 & 41.3 \\
\hline Fresh water & 93.2 & 67 & 63.3 \\
\hline
\end{tabular}
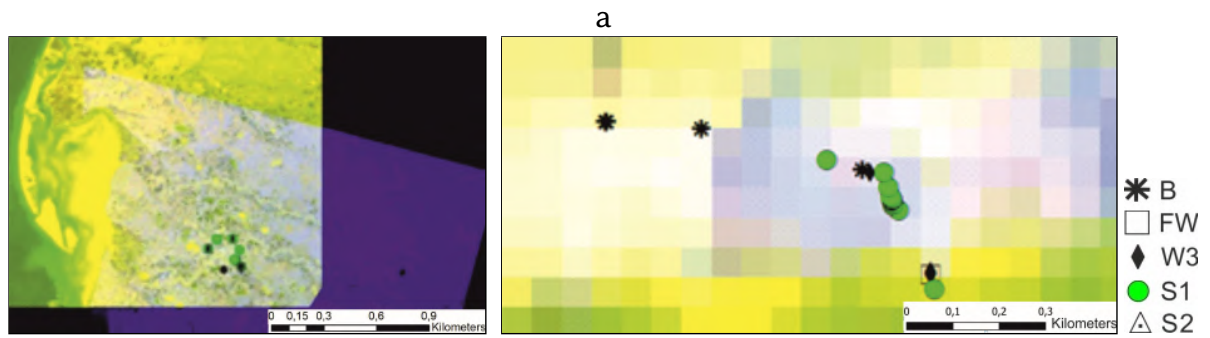

b
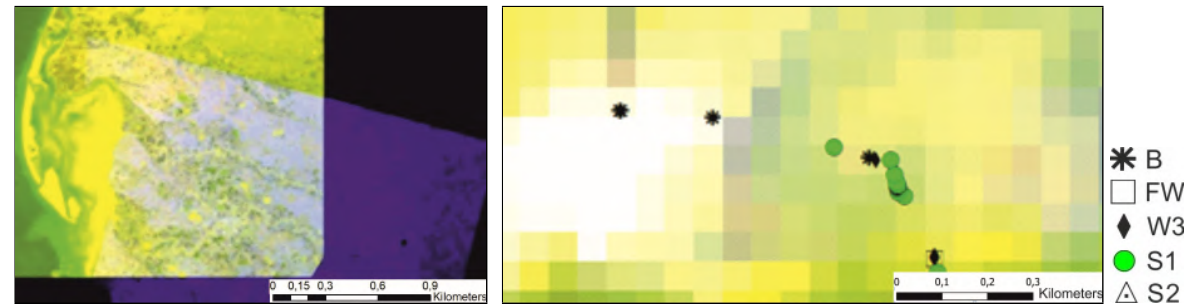

Figure 6: Visual representation of synergy Sentinel-2 and Sentinel- $1: \mathrm{R}^{1} \mathrm{G}^{1} \mathrm{~B}^{1}=(4,3, \mathrm{VV})(\mathrm{a})$; $\mathrm{R}^{2} \mathrm{G}^{2} \mathrm{~B}^{2}=(4,3, \mathrm{VH})(\mathrm{b})$.

\section{Table 6}

Results of ML classification based on contextual analysis.

\begin{tabular}{cccc}
\hline Class & \multicolumn{3}{c}{$\begin{array}{c}\text { \% of matches with test set } \\
\text { Sentinel-2 \& Sentinel-1 }\end{array}$} \\
$\begin{array}{c}\text { SGB }=(4,3,2) \\
\mathrm{R}^{1} \mathrm{G}^{1} \mathrm{~B}^{1}=(4,3, \mathrm{VV})\end{array}$ & $\begin{array}{c}\text { Sentinel-2 \& Sentinel-1 } \\
\mathrm{R}^{2} \mathrm{G}^{2} \mathrm{~B}^{2}=(4,3, \mathrm{HV})\end{array}$ \\
\hline $\begin{array}{c}\text { Sedge, moss, } \\
\text { low-shrub wetland }\end{array}$ & 60.7 & 23.6 & 23.5 \\
Erect dwarf-shrub tundra & 94.2 & 100 & 100 \\
Low-shrub tundra & 97.9 & 50.3 & 47.6 \\
Barrens & 99.6 & 76.9 & 76.9 \\
Fresh water & 90.5 & 100 & 100 \\
\hline
\end{tabular}


a

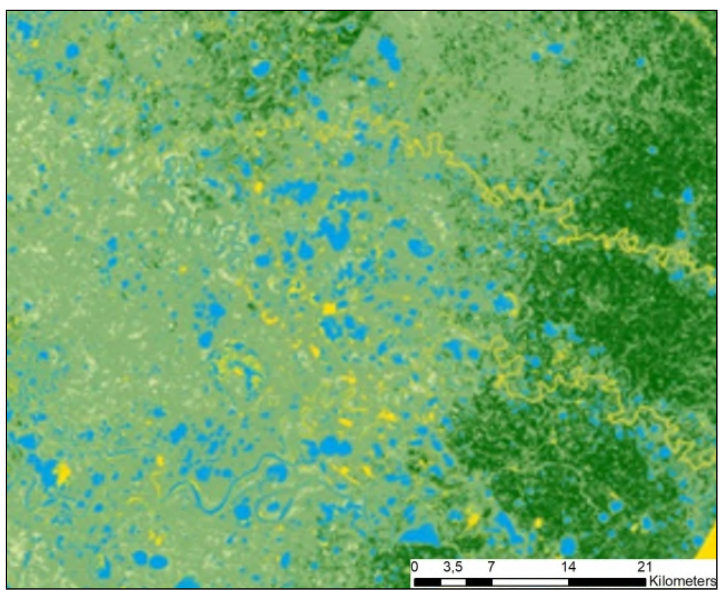

\section{$\square$ B $\square$ FW $\square$ W3 $\square$ S1 $\square$ S2}

b

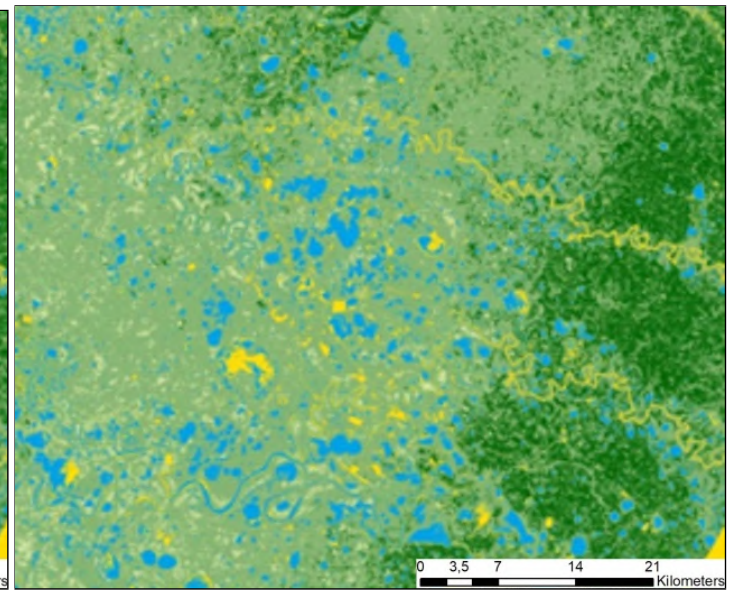

Figure 7: Synergy of Sentinel- 1 and Sentinel-2 classification results: $\mathrm{R}^{1} \mathrm{G}^{1} \mathrm{~B}^{1}=(4,3, \mathrm{VV})(\mathrm{a})$; $\mathrm{R}^{2} \mathrm{G}^{2} \mathrm{~B}^{2}=(4,3, \mathrm{VH})(\mathrm{b})$.

In case of pixel-wise classification, the use of $\mathrm{VV}$ and $\mathrm{VH}$ polarizations increases the accuracy by $6 \%$ for the Erect dwarf-shrub, while in case of contextual analysis - for classes Erect dwarfshrub tundra and Fresh Water up to 100\% (Erect dwarf-shrub and Fresh Water - by 6\% and 10\%, respectively).

\section{Discussion}

For the period 2016-2018 in the Bovanenkovo surroundings, there is a general reduction of areas unoccupied with vegetation that is consistent with the studies demonstrating Arctic greening $[7,8,21]$.

It is obvious that even for a band combination, which is inefficient from the point of view of clear distinction of vegetation classes, an additional use of SAR data increases the results of one of the vegetation classes. This is consistent with other studies $[17,18]$ in the sense that co-processing of optical and SAR data provides the improved results as compared to the use of only optical data.

Therefore, to obtain the comprehensive assessment of synergy of Sentinel-1 and Sentinel-2 data in the context of Sentinel-2 band combinations for Central Yamal, it is necessary to classify the study territory scenes for cases of all possible band combinations and full set of Sentinel-2 bands.

\section{Conclusion}

Due to rapidly advancing climate change, there is a great need for monitoring Arctic vegetation. Substantial changes in vegetation cover and its composition have been observed in many areas across the Arctic. Because of regional variations in vegetation dynamics, there is a need for the 
detailed analysis of vegetation patterns and changes, which may be driven by local factors (i.e., disturbance regimes). Our goal was to develop remote-sensing tools for monitoring (and better understanding) of variations in the vegetation system of Central Yamal.

ML classification based on high-resolution multispectral data as well as visual pattern analysis of combined multispectral and SAR data show high-performance in obtaining the information on five land cover classes of Central Yamal:

1. Open spaces (free from vegetation).

2. Open aquatic areas.

3. Sedge, moss, shrub wetlands.

4. Tundra vegetation with a height of less than $40 \mathrm{~cm}$.

5. Tundra vegetation with a height of more than $40 \mathrm{~cm}$.

The use of Sentinel-2 and Sentinel-1 synergy in various band combinations may be efficient for identifying anthropogenic (Fresh Water, Barrens) and natural objects (Sedge, moss, low-shrub wetland, Erect dwarf-shrub tundra, Low-shrub tundra).

In particular, the combination of high-resolution spectral (10 m, Red, Green) and SAR (VV and $\mathrm{VH}$ polarizations) data increases the classification accuracy for Fresh Water and Erect dwarf-shrub tundra classes up to $100 \%$ (by $10 \%$ and $6 \%$, respectively). The impact of VV and VH polarizations differs insignificantly.

The study findings may contribute to the mapping of arctic vegetation, since the methodology improves the recognition accuracy. The constructed maps are of interest for assessing the ecological state and dynamics of vegetation cover.

\section{Acknowledgments}

This study was carried out as a part of State Task (Projects 0306-2021-0007, 121031200178-8) of the Institute for Water and Environmental Problems SB RAS with the financial support of the Non-Profit Partnership "Russian Center for Arctic Development" (Salekhard).

\section{References}

[1] Raynolds M.K., Walker D.A., Balser A., Bay C., Campbell M., Cherosov M.M., Daniels F.J., Eidesen P.B., Ermokhina K.A., Frost G.V., Jedrzejek B., Jorgenson M.T., Kennedy B.E., Kholod S.S., Lavrinenko I.A., Lavrinenko O.V., Magnusson B., Matveyeva N.V., Metusalemsson S., Nilsen L., Olthof I., Pospelov I.N., Pospelova E.B., Pouliot D., Razzhivin V., Schaepman-Strub G., Šibik J., Telyatnikov M.Y. Troeva E. A raster version of the circumpolar arctic vegetation map (CAVM) // Remote Sensing of Environment. 2019. Vol. 232. 111297. DOI:10.1016/j.rse.2019.111297.

[2] Walker D.A., Raynolds M.K., Daniëls F.J.A., Einarsson E., Elvebakk A., Gould W.A., Katenin A.E., Kholod S.S., Markon C.J., Melnikov E.S., Moskalenko N.G., Talbot S.S., Yurtsev B.A., CAVM Team. The circumpolar arctic vegetation map // Journal of Vegetation Science. 2005. Vol. 16. Is. 3. P. 267-282. DOI:1100-9233(2005)016. 
[3] Riihimaki H., Luoto M., Heiskanen J. Estimating fractional cover of tundra vegetation at multiple scales using unmanned aerial systems and optical satellite data // Remote Sensing of Environment. 2019. Vol. 224. P. 119-132. DOI:10.1016/j.rse.2019.01.030.

[4] Tyrtikov A.P. The influence of vegetation cover on freezing and thawing of soils. Moscow, 1969.

[5] Bartsch A., Widhalm B., Leibman M., Ermokhina K., Kumpula T., Skarin A., Wilcox E.J., Jones B.M., Frost G.V., Höfler A., Pointner G. Feasibility of tundra vegetation height retrieval from Sentinel-1 and Sentinel-2 data // Remote Sensing of Environment. 2020. Vol. 237. 111515. DOI:10.1016/j.rse.2019.111515.

[6] Bartalev S.A., Egorov V.A., Yershov D.V., Isaev A.S., Lupyan E.A., Plotnikov D.E., Uvarov I.A. Satellite mapping of vegetation cover of Russia according to MODIS data // Modern Problems of Remote Sensing of the Earth from Space. 2011. Vol. 8. No. 4. P. 285-302.

[7] Walker D.A., Epstein H.E., Raynolds M.K., Kuss P., Kopecky M.A., Frost G.V., Daniëls F.J.A., Leibman M.O., Moskalenko N.G., Matyshak G.V., Khitun O.V. Environment, vegetation and greenness (NDVI) along the North America and Eurasia Arctic transects // Environmental Research Letters. 2012. Vol. 7. 015504.

[8] Epstein H.E. et al. Spatial patterns of arctic tundra vegetation properties on different soils along the Eurasia Arctic Transect, and insights for a changing Arctic // Environment Research Letters. 2021. Vol. 16. 014008 DOI:10.1088/1748-9326/abc9e3.

[9] Bartalev S.A., Egorov V.A., Zharko V.O., Lupyan E.A., Plotnikov D.E., Khvostikov S.A., Shabanov N.V. Satellite mapping of vegetation cover of Russia. Moscow: SRI RAS, 2016. $208 \mathrm{p}$.

[10] Puzanov A.V., Tsymbaley Yu.M., Alekseev I.A., Kovalevskaya N.M., Plutalova T.G. Remote study of vegetation cover during construction works (by the example of Vostochny cosmodrome) // Geography and Natural Resources. 2018. No. 2. P. 162-171.

[11] Kupková L., Červená L., Suchá R., Jakešová L., Zagajewski B., Březina S., Albrechtová J. Classification of Tundra vegetation in the Krkonoše Mts. national park using APEX, AISA Dual and Sentinel-2A data // European Journal of Remote Sensing. 2017. Vol. 50. No. 1. P. 29-46. DOI:10.1080/22797254.2017.1274573.

[12] Europe land-cover mapped in $10 \mathrm{~m}$ resolution. Available at: http://www.esa.int/ESA Multimedia/Images/2020/03/Europe_land-cover_mapped_in_10_m_resolution.

[13] Lavrinenko I.A. Map of technogenic disturbance of vegetation cover of Nenets autonomous okrug // Modern Problems of Remote Sensing of the Earth from Space. 2018. Vol. 15. No. 2. P. 128-136.

[14] Saatchi S.S., Rignot E. Classification of boreal forest cover types using SAR images // Remote Sensing of Environment. 1997. Vol. 60. Iss. 3. P. 270-281. DOI:10.1016/S00344257(96)00181-2.

[15] Collingwood A., Treitz P., Charbonneau F., Atkinsons D. Artificial neural network modeling of high arctic phytomass using synthetic aperture radar and multispectral data // Remote Sensing. 2014. Vol. 6. P. 2134-2153.

[16] Whitcomb J., Moghaddam M., McDonald K., Kellndorfer J., Podest E. Mapping vegetated wetlands of Alaska using L-band radar satellite imagery // Canadian Journal of Remote Sensing. 2009. Vol. 37. P. 54-72.

[17] Niculescu S., Lardeux C., Hanganu J. Synergy between Sentinel-1 radar time series and 
Sentinel-2 optical for the mapping of restored areas in Danube delta // Proceedings of the International Cartographic Association. 2018. Vol. 1. No. 82. DOI:10.5194/ica-proc-1-822018.

[18] Ullmann T., Schmitt A., Roth A., Duffe J., Dech S., Hubberten H.W., Baumhauer R. Land cover characterization and classification of arctic tundra environments by means of polarized synthetic aperture X- and C-band radar (PolSAR) and Landsat 8 multispectral imagery - richards Island, Canada // Remote Sensing. 2014. Vol. 6. P. 8565-8593. DOI:10.3390/rs6098565.

[19] Copernicus land cover. Available at: https://and.copernicus.eu/user-corner/ technical-library/clcplus-draft-technical-specifications- $v 4$.

[20] Sentinel 2 bands and combinations. Available at: https://gisgeography.com/ sentinel-2-bands-combinations.

[21] NASA studies details of a greening Arctic. 2017. Available at: https://www.nasa.gov/ feature/goddard/2016/nasa-studies-details-of-a-greening-arctic. 